Plant Pathology \& Quarantine — Doi 10.5943/ppq/2/2/7

\title{
Molecular identification of Macrophomina phaseolina by microsatellite-based fingerprint
}

\section{Asran-Amal A}

Agricultural Research Centre, Plant Pathology Research Institute, Cotton Diseases Section, 9- Gamaa St., Giza, Egypt

Asran-Amal A 2012 - Molecular identification of Macrophomina phaseolina by microsatellite-based fingerprint. Plant Pathology \& Quarantine 2(2), 143-151, doi 10.5943/ppq/2/2/7

The microsatellite primers (ATG)5, (TAGG)4 and a primer derived from the intergenic spacer regions (T3B) were employed to distinguish 16 fungal species. Distinctive and reproducible sets of amplification products were observed for the 16 species, with the numbers and sizes of the amplification products characteristic for each species. Microsatellite primer PCR yielded highly reproducible and complex genomic fingerprints, with several bands ranging in size from 200 to 3000 bp. Amplification products, regardless of the tested primers, were obtained from Macrophomina phaseolina DNA, each primer pair yielded a single DNA fragment of the expected size: 1100, 760, and 530 bp for (ATG)5, (TAGG)4, and (T3B), respectively. Cluster analysis separated the isolates into two major groups with intermix of isolates from two sampling locations. The three primers tested amplify species-specific microsatellites that unambiguously distinguish $M$. phaseolina from other fungal species tested. The unique banding patterns of $M$. phaseolina from 16 isolates make these primers valuable as diagnostic markers for the respective species. These distinct fingerprinting patterns can be used as diagnostic tools to local pathogen populations.

Keywords - Botryosphaeriaceae - cotton - Microsatellite markers - soil-borne fungi

Article Information

Received 4 May 2012

Accepted 3 July 2012

Published online 15 September 2012

*Corresponding author: Asran-Amal - e-mail - asran.amal@gmail.com

\section{Introduction}

Agricultural and wild ecosystems may interact through shared pathogens such as Macrophomina phaseolina (Tassi) Goid., a generalist clonal fungus with more than 284 plant hosts that it is likely to become more important under climate change scenarios of increased heat and drought stress (Ali \& Dennis 1992, Saleh et al. 2010, Mihail \& Taylor 1992). M. phaseolina is a seed and soil-borne pathogen with a wide distribution and host range (Dhingra \& Sinclair 1978). The importance of $M$. phaseolina as the cause of ashy stem (charcoal rot) of cotton in Egypt is underestimated. This view has come from the observation that during the last 50 years, $M$. phaseolina on cotton was almost absent from the literature of cotton diseases in Egypt, and only a handful of studies, most of them not dealing with $M$. phaseolina per se, were found in this literature (Mostafa 1959, Sabet \& Khan 1969, Aly et al. 1996, AbdElsalam 2011a). This lack of concern is not justifiable because this fungus is of widespread distribution in Egyptian soil and it is easily and 


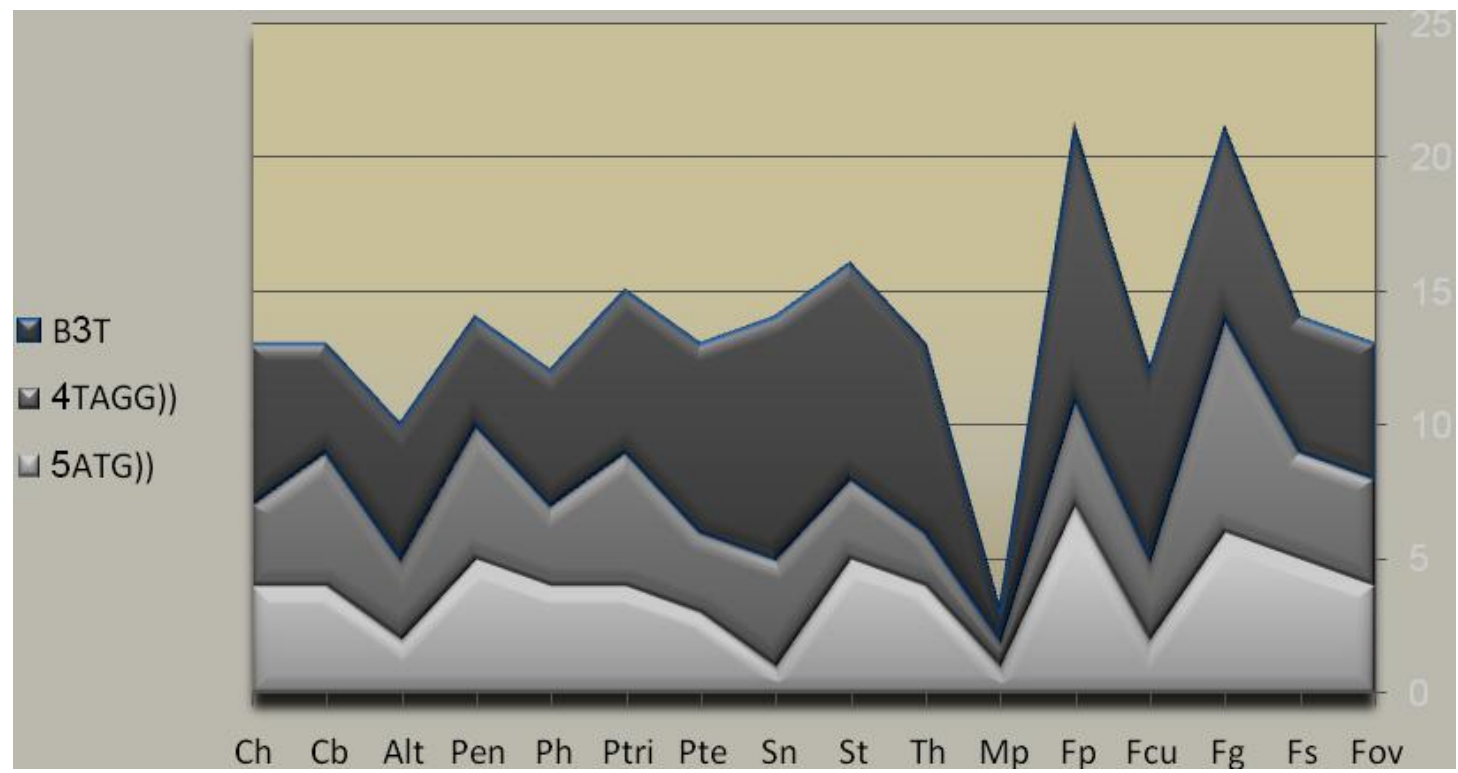

Fig. 1 - Polymorphism barcode obtained by three repeat-based primers among 16 fungal species isolates tested for MP-PCR specificty

frequently isolated from cotton roots particularly during the late period of the growing season. Molecular markers are useful tools for detecting genetic variation within populations of $M$. phaseolina (Jana et al. 2005). RAPD markers have been considered suitable for measuring genetic relatedness, detecting variation within and between $M$. phaseolina populations (Alvaro et al. 2003, Fuhlbohm 1997 and Jana et al. 2003, Omar et al. 2007, Su et al. 2001). AFLP genotype and geographical origin of $M$. phaseolina from Mexico and other countries gave a clear differentiation between Mexican and non-Mexican isolates (Reyes-Franco et al. 2006). Amplification of ITS1 region of $M$. phaseolina, root rot pathogen of Citrus reticulata the rDNA can be considered as a rapid technique for identifying pathogens successfully in all cases (Saleh et al. 2010, Chakraborty et al. 2011). Amplification of the ITS region using primers ITS1 and ITS4 produced only one DNA fragment of $620 \mathrm{bp}$. None of the isolates were differentiated through PCR-RFLP. The results demonstrated genetic variability among Brazilian isolates of $M$. phaseolina and showed that one single root can harbor more than one haplotype (Alvaro et al. 2003). The RFLP analysis was not suitable for detection of genetic diversity of $M$. phaseolina (Purkayastha et al. 2006).

Recently, microsatellite primer PCR (MP-PCR) has been extensively applied for various fungal molecular biological studies such as genetic diversity (Abd-Elsalam et al. 2010, Mwang'Ombe et al. 2007) pathogen identification and differentiation (Alves et al. 2007) and fungal evolution (Wöstemeyer et al. 2002). Microsatellites have been used in several epidemiological studies of phytopathogenic fungi (Guerin et al. 2007, Raboin et al. 2007). Microsatellite dinucleotide specific-primers were designed based on microsatellite repeats of sequences present in the genome of Mycosphaerella graminicola (Abd-Elsalam et al. 2011a). Simple-sequence repeats (SSR) primers have been generated and then applied for the genetic analysis of $M$. phaseolina isolates (Vandemark et al. 2000, Su et al. 2001, Jana et al. 2003, 2005, Purkayastha et al. 2008, Baird et al. 2010, Ariasa et al. 2011, Mahdizadeh et al. 2012). 
Plant Pathology \& Quarantine — Doi 10.5943/ppq/2/2/7

Table 1 Fungal isolates used in the current study.

\begin{tabular}{cclcc}
\hline $\begin{array}{c}\text { Isolate } \\
\text { No. }\end{array}$ & $\begin{array}{c}\text { Fungal species } \\
\text { abbrevation }\end{array}$ & Fungal species & Host & Geographic origin \\
\hline 1 & Fov & Fusarium oxysporum f. sp. vasinfectum & Cotton & Egypt \\
2 & $\mathrm{Fs}$ & F. solani & Cotton & Egypt \\
3 & $\mathrm{Fg}$ & F. graminearum & Wheat & Germany \\
4 & $\mathrm{Fcu}$ & F. culmorum & Wheat & Germany \\
5 & $\mathrm{Fp}$ & F. poae & Wheat & Germany \\
6 & $\mathrm{Mp}$ & Macrophomina phaseolina & Cotton & Egypt \\
7 & $\mathrm{Th}$ & Trichoderma harizinum & Cotton & Egypt \\
8 & $\mathrm{St}$ & Septoria tritici & Wheat & Germany \\
9 & $\mathrm{Sn}$ & Stagonospora nodorum & Wheat & Germany \\
10 & $\mathrm{Pte}$ & Pyrenophora teres & Barley & Germany \\
11 & $\mathrm{Ptr}$ & Pyrenophora tritici-repentis. & Wheat & Germany \\
12 & $\mathrm{Ph}$ & Pseudocercosporella herpotrichoides & Wheat & Germany \\
13 & $\mathrm{Pen}$ & Penicillium sp. & Wheat & Germany \\
14 & $\mathrm{Alt}$ & Alternaria sp. & Wheat & Germany \\
15 & $\mathrm{Cb}$ & Cercospora beticola & Sugerbeet & Germany \\
16 & $\mathrm{Ch}$ & Chaetomium sp. & Cotton & Egypt \\
& & & & \\
\hline
\end{tabular}

Currently intensive work is ongoing for developing microsatellite primers as a diagnostic tool for detection of $M$. phaseolina in cotton. In the current study, three microsatellite primers designed based on microsatellite sequences (Bahkali et al. 2012) were used to identify $M$. phaseolina based on one single marker. To our knowledge, the use of microsatellite typing method for molecular diagnosis of $M$. phaseolina isolated from cotton has not been reported before.

\section{Materials and Methods}

\section{Fungal isolates}

Sixteen fungal species isolates used in this study are listed (Table 1) and $16 M$. phaseolina isolates were obtained from different cotton-producing areas (Table 2). Pure cultures were grown on potato dextrose broth (PDB) for 10 days at $25-28^{\circ} \mathrm{C}$ in the dark. Mycelia were harvested by filtration through filter paper (Whatman No. 1). The harvested mycelia were either used immediately for DNA extraction or stored at $-70^{\circ} \mathrm{C}$ until use.

\section{DNA extraction}

A modification of the traditional sodium dodecyl sulfate (SDS) extraction procedure was adopted. Fresh fungal mats (100 mg) were homogenized in $400 \mu \mathrm{L}$ sterile salt homogenizing buffer (200 mM Tris-HCl, pH 8.5, $250 \mathrm{mM}$ $\mathrm{NaCl}, 25 \mathrm{mM}$ EDTA, 0.5\% SDS). Next, $6 \mu \mathrm{L} 20$ $\mathrm{mg} / \mathrm{mL}$ RNase A was added and mixed well. The samples were incubated at $65^{\circ} \mathrm{C}$ for $10 \mathrm{~min}$, after which $130 \mu \mathrm{L} 3 \mathrm{M}$ sodium acetate, $\mathrm{pH}$ 5.2, was added to each sample. Samples were vortexed for $30 \mathrm{~s}$ at maximum speed, and incubated at $20^{\circ} \mathrm{C}$ for $10 \mathrm{~min}$. The lysate was centrifuged at $13,000 \mathrm{rpm}$ at $4^{\circ} \mathrm{C}$ for $15 \mathrm{~min}$, and the supernatant was transferred to fresh tubes. An equal volume of isopropanol was added to each sample, and after mixing well, samples were incubated at $-20^{\circ} \mathrm{C}$ for $10 \mathrm{~min}$. Samples were then centrifuged for $20 \mathrm{~min}$ at $4^{\circ} \mathrm{C}$, at $6000 \mathrm{rpm}$. The DNA pellets were washed twice using 700 $\mu \mathrm{L}$ washing solution (100 and $70 \%$ ethanol, respectively). The DNA pellets were subsequently air dried in an oven at $40^{\circ} \mathrm{C}$ for at least $10 \mathrm{~min}$. The resultant DNA pellet was then resuspended in $100 \mu \mathrm{L} 1 \mathrm{X}$ TE $(10 \mathrm{mM}$ Tris- $\mathrm{HCl}$, 


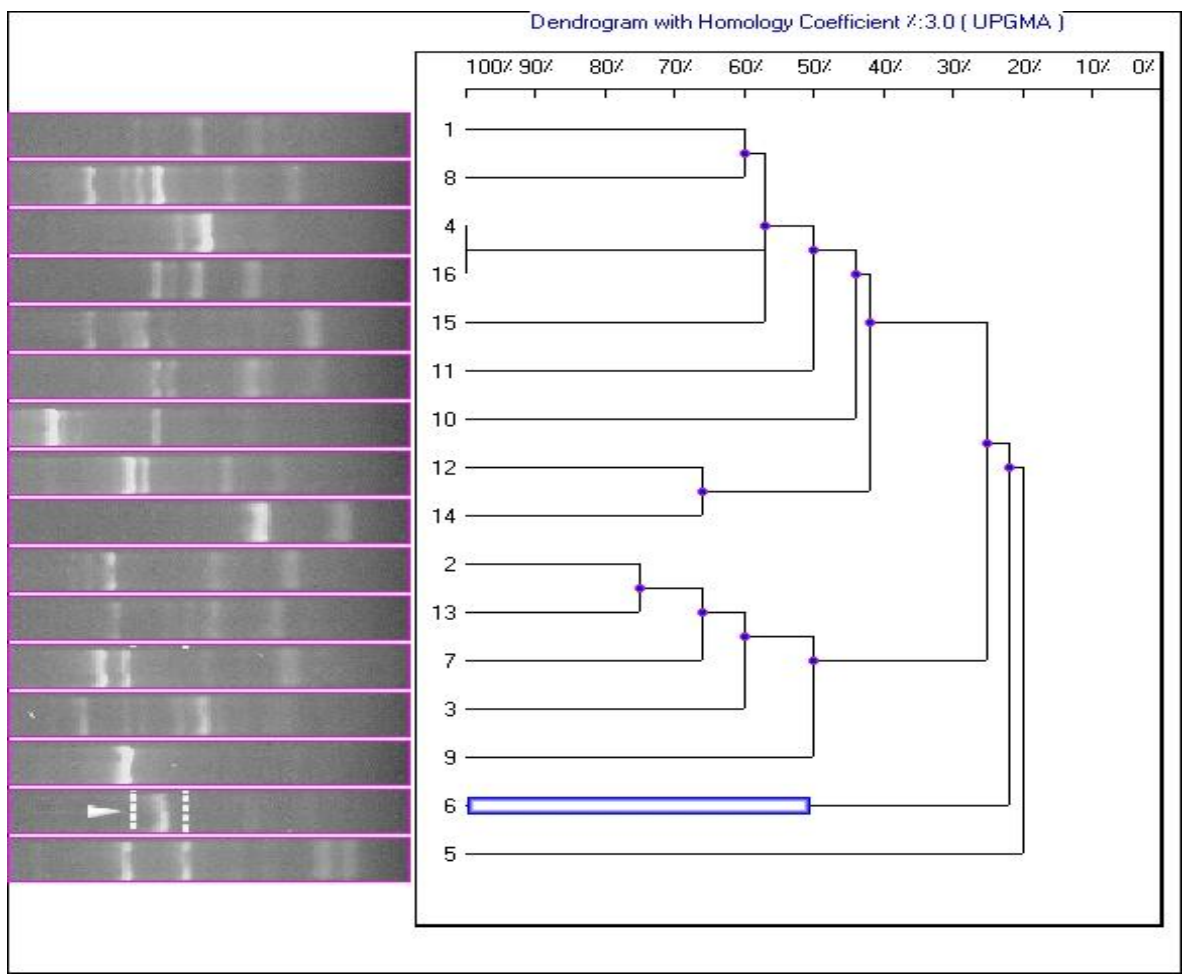

Fig. 2 - Digitized dendrogram from (ATG) 5 microsatellite-polymerase chain reaction profiles for 15 fungal species and Macrophomina phaseolina (6) created with Bionumerics using Pearson's correlation coefficient and unweighted pair group method with arithmetic mean (UPGMA).

1 mM EDTA) buffer, $\mathrm{pH} 8.0$ (Abd-Elsalam et al. 2011b).

\section{Microsatellite directed PCR}

Microsatellite primed-PCR amplifications PCR was performed using a thermal cycler (Techne TC-312, Techne, Stone, UK) in $50 \mu 1$ volumes containing $50 \mathrm{ng}$ fungal DNA template, $10 \mathrm{pmol}$ of the tested primers (Table 3), $0.2 \mathrm{mM}$ of each dNTP, $2.0 \mathrm{mM} \mathrm{MgCl2,} 1$ x Promega Taq Polymerase Buffer (10 mM Tris-HCl, pH 9.0, 50 $\mathrm{mM} \mathrm{KCl}$, and $0.1 \%$ Triton X-100, Promega, WI, USA), and 1.5 U of Taq Polymerase (Promega). Amplification was performed using the following parameters: an initial pre-heat for 3 min at $95{ }^{\circ} \mathrm{C}, 37$ cycles of denaturation at $94{ }^{\circ} \mathrm{C}$ for $1 \mathrm{~min}$, annealing at $50{ }^{\circ} \mathrm{C}$ for $1 \mathrm{~min}$, extension at $72{ }^{\circ} \mathrm{C}$ for $1.5 \mathrm{~min}$, and a final extension at $72{ }^{\circ} \mathrm{C}$ for $10 \mathrm{~min}$. PCR products were separated in $1.5 \%$ agarose gels in Trisacetate (TAE) buffer. DNA was visualized by
UV flourescence after staining with ethidium bromide. UVIsoft analysis packages (Gel Documentation and Analysis Systems, Uvitec, Cambridge, UK) were used to capture the image and calculate the molecular sizes.

Visual and computer-assisted analysis of MPPCR patterns

Fragments profiles obtained were calculated for polymorphism by visual observation. Visible bands among isolates with the same migration distance were considered no different. Microsatellite fragments were scored as present (1) or absent (0) among the isolates. Only reproducible bands in repeated PCR amplification were considered for analyses. All MP-PCR patterns were analyzed with Fingerprinting Software (Gel Documentation and Analysis Systems, Uvitec, Cambridge, UK). Bands were automatically identified, verified and edited manually. Dendrograms were generated 
Table 2 Macrophomina phaseolina (Mp) isolates collected from two major cotton-producing areas and total number of amplified fragments obtained by the tested primers used in this study.

\begin{tabular}{clllllc}
\hline $\begin{array}{c}\text { Isolate } \\
\text { No. }\end{array}$ & Mp isolates & Geographic & Region & \multicolumn{2}{c}{ Fragment number obtained } \\
\cline { 5 - 7 } & & & & (ATG)5 & (TAGG)4 & T3B \\
\hline 1 & Macrophomina phaseolina & Beheira & Lower Egypt & 1 & 1 & 1 \\
2 & Macrophomina phaseolina & Beheira & Lower Egypt & 1 & 1 & 1 \\
3 & Macrophomina phaseolina & Daqahliya & Lower Egypt & 1 & 1 & 1 \\
4 & Macrophomina phaseolina & Daqahliya & Lower Egypt & 1 & 1 & 1 \\
5 & Macrophomina phaseolina & Sharqiya & Lower Egypt & 1 & 1 & 1 \\
6 & Macrophomina phaseolina & Sharqiya & Lower Egypt & 1 & 1 & 1 \\
7 & Macrophomina phaseolina & Kafr El-Sheikh & Lower Egypt & 1 & 1 & 1 \\
8 & Macrophomina phaseolina & Kafr El-Sheikh & Lower Egypt & 1 & 1 & 1 \\
9 & Macrophomina phaseolina & Giza & Upper Egypt & 1 & 1 & 1 \\
10 & Macrophomina phaseolina & Giza & Upper Egypt & 1 & 1 & 1 \\
11 & Macrophomina phaseolina & Minya & Upper Egypt & 1 & 1 & 1 \\
12 & Macrophomina phaseolina & Minya & Upper Egypt & 1 & 1 & 1 \\
13 & Macrophomina phaseolina & Assiut & Upper Egypt & 1 & 1 & 1 \\
14 & Macrophomina phaseolina & Assiut & Upper Egypt & 1 & 1 & 1 \\
15 & Macrophomina phaseolina & Sohag & Upper Egypt & 1 & 1 & 1 \\
16 & Macrophomina phaseolina & Sohag & Upper Egypt & 1 & 1 & 1 \\
\hline
\end{tabular}

by the hierarchic unweighted pair-group method with arithmetic averages (UPGMA) cluster algorithm.

\section{Results}

To determine whether the PCR fingerprint technique could be employed for species identification, each sample of genomic DNA from 16 fungal species was amplified separately with three primers, the microsatellite repeats (ATG)5, (TAGG)4, and a primer derived from the intergenic spacer regions (T3B). (ATG)5, (TAGG)4, and (T3B) primers gave single amplification products at $50^{\circ}$ annealing temperatures, because it always led to high polymorphic banding patterns that were suitable for inter-species comparisons. The patterns resulting from the T3B and (TAGG) 4 test were more distinct.

The (ATG)5, (TAGG)4, and (T3B) primers amplified single unique DNA fragments of approximately 1100, 760, and $530 \mathrm{bp}$, respectively from $M$. phaseolina isolates (Table 2 ), whereas no amplification was achieved with DNA isolated from other fungal species. The numbers of scorable bands were between 1 to 10 depending on the primer combination and about $68 \%$ of the scored bands were polymorphic between different fungal isolates (Fig. 1).

To check the effectiveness of primers in the detection of intraspecific polymorphisms, experiments were performed by analysing isolates of $M$. phaseolina. Amplification of DNA from various $M$. phaseolina isolates using microsatellite repeat primers resulted in a single distinguishable marker. The discriminating powers of the three primers used in this study were nearly the same. Cluster analyses were performed on the genomic fingerprints generated by each of the primers tested. Three dendrograms were generated with the UPGMA method and are shown in Figs. 2, 3 and 4.

For all primers analyzed the clustering of the isolates was species-specific. Isolates belonging to the same species typically clustered together at similarity values greater than $80 \%$. The observed intra-isolates homologies were mostly in the range of about 80 to $95 \%$, similar to those obtained with the dendrogram produced by T3B-based fingerprinting. There was no clear-cut relationship between clustering in the MP-PCR dendrogram and geographic origin of 


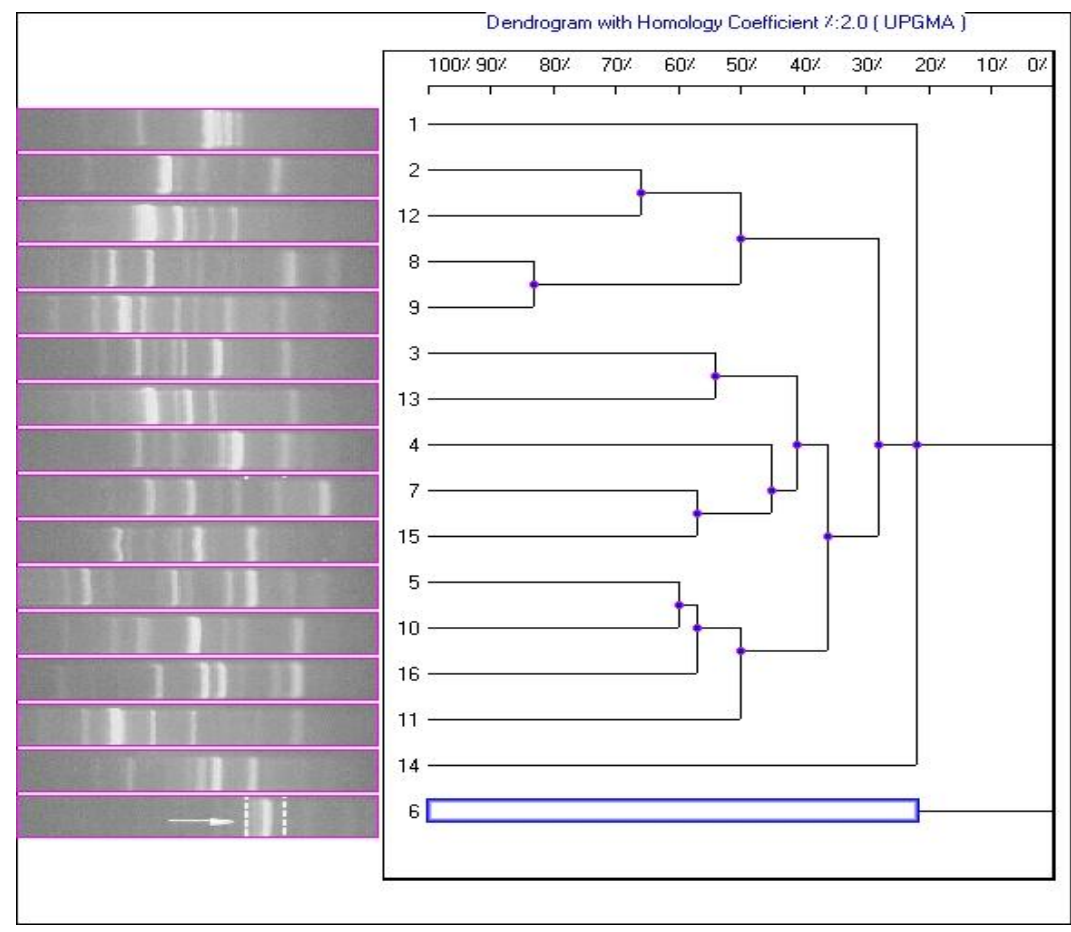

Fig. 3 - Digitized dendrogram from T3B microsatellite-polymerase chain reaction profiles for 15 fungal species and Macrophomina phaseolina (6) created with Bionumerics using Pearson's correlation coefficient and unweighted pair group method with arithmetic mean (UPGMA).

tested isolates.

\section{Discussion}

Ashy stem (charcoal rot) of cotton, caused by M. phaseolina, is an important and widely prevalent disease of cotton. Simple sequence repeats (SSRs) or microsatellites have been shown to be one of the most powerful genetic markers in mycology (Bahkali et al. 2012). Microsatellite markers have been generated for a number of plant pathogenic fungi (Saharan et al. 2007, Purkayastha et al. 2008, Baird et al. 2010, Ariasa et al. 2011, Mahdizadeh et al. 2012). However, there are only a few reports on the molecular characterization of $M$. phaseolina isolates in relation to host specificity (Vandemark et al. 2000, Su et al. 2001, Omar et al. 2007).

In this study, we have focused on microsatellite-based methods supplying patterns specific for particular $M$. phaseolina isolates. Based on the specific PCR fingerprints and the high interspecies variation of these banding patterns, a clear distinction between all species was possible. This study also revealed that a single marker can clearly distinguish $M$. phaseolina from other fungal species at the molecular level. The ability of the selected primers to produce species-specific fingerprints was apparent. Isolates that were deemed to represent different species according to conventional morphological as well as molecular phylogenetic criteria gave rise to distinct PCR fingerprints, whereas isolates of the same species had similar banding patterns.

T3B was the most successful primer because it always led to high polymorphic banding patterns that were suitable for interspecies comparisons. Complex fingerprints are generated, allowing detection of polymorphisms at inter- and intraspecific levels and subsequent identification (Godoy et al. 2004). The high discriminatory power (Burgess et al. 2001, Grünig et al. 2001) of this technique explains why it revealed a great heterogeneity 


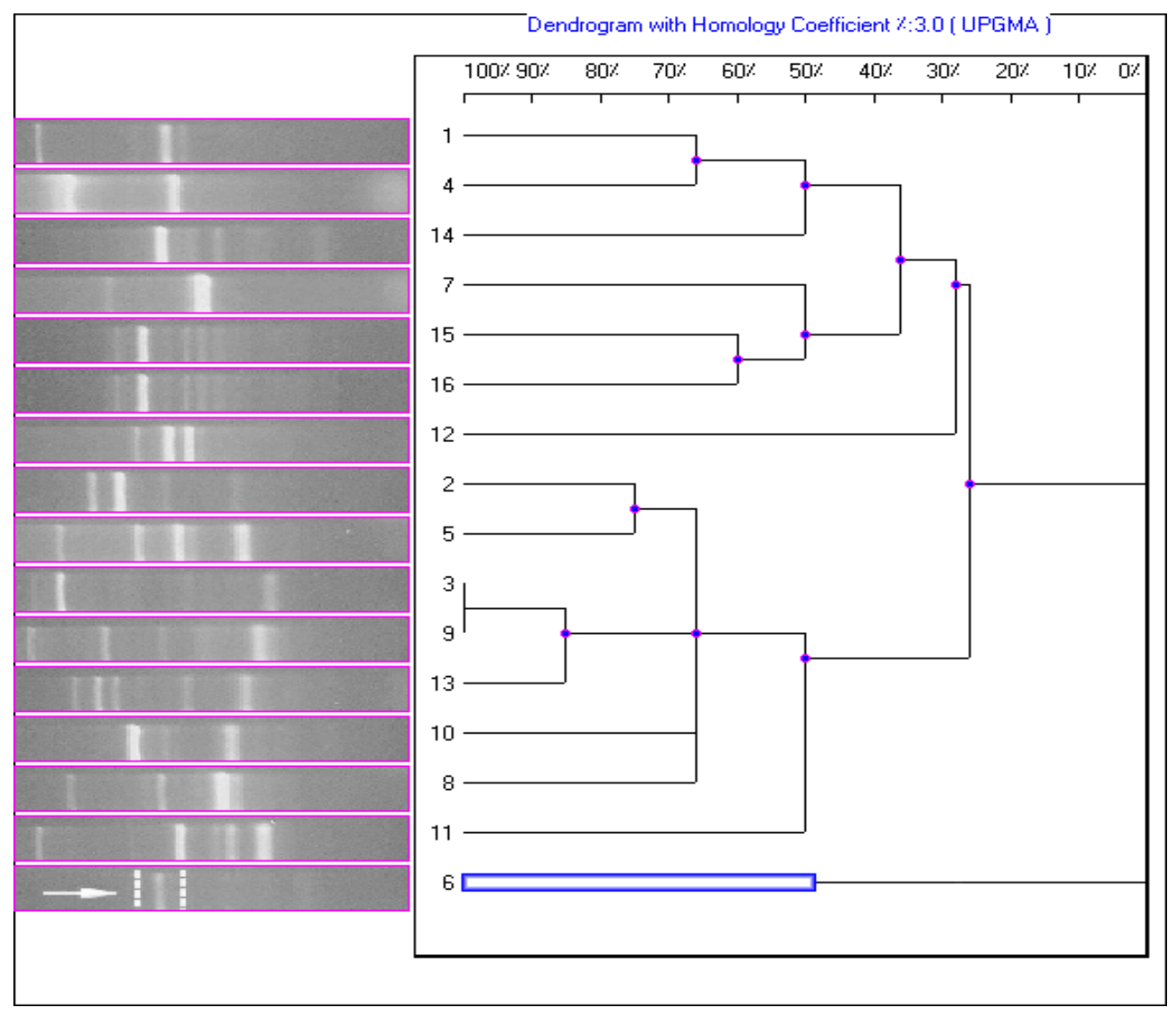

Fig. 4 - Digitized dendrogram from (TAGG)4 microsatellite-polymerase chain reaction profiles for 15 fungal species and Macrophomina phaseolina (6) created with Bionumerics using Pearson's correlation coefficient and unweighted pair group method with arithmetic mean (UPGMA).

among isolates. Single alleles per marker on each sample have been reported previously when 13 microsatellite markers were tested on $M$. phaseolina isolates from soybean (Baird et al. 2010) and from other plant hosts (Baird et al. 2010, Arias et al 2011, Mahdizadeh et al. 2012). Arias et al. (2011) provided 147 new microsatellite markers that will significantly enrich the molecular resources for $M$. phaseolina.

The low length polymorphism of tetranucleotide repeats obtained in the current study could be clarified by the fact that in fungi short stretches of trinucleotide repeat motifs exist as compared to higher organisms. Trinucleotide and dinucleotide repeat primers are the most frequent motifs in fungi (Karaoglu et al. 2005, Jany et al. 2006).

In conclusion, the results presented herein indicate that a microsatellite technique provides an efficient tool for the identification of poly and monomorphic loci that can be used to monitor the genetic differences between phytopathogenic fungi. In the next few years complete genome sequences might be available for $M$. phaseolina also, and a combination of microsatellites markers with other genomic methods will certainly accelerate the effort to characterize this fungus. Future research is warranted to develop more microsatellite primers with a wider array of $M$. phaseolina. 
Table 3 Microsatellite primers used in the current study and their length, GC content, optimum annealing temperature (AT), size range of fragments

\begin{tabular}{cccccc}
\hline $\begin{array}{c}\text { Primers } \\
\text { name }\end{array}$ & Sequence $\left(\mathbf{5}^{\prime} \mathbf{- 3}^{\prime}\right)$ & Length & $\begin{array}{c}\text { GC } \\
\text { Content } \\
(\boldsymbol{\%})\end{array}$ & $\begin{array}{c}\text { Optimum } \\
\mathbf{A T}\left(\mathbf{(}^{\circ} \mathbf{C}\right)\end{array}$ & $\begin{array}{c}\text { Range of } \\
\text { fragment size } \\
(\mathbf{b p})\end{array}$ \\
\hline (ATG)5 & ATG ATG ATG ATG ATG & 15 & 33.3 & 50 & $200-3000$ \\
$($ TAGG)4 & TAGG TAGG TAGG TAGG & 16 & 50.0 & 50 & $200-2000$ \\
T3B & AGG TCG CGG GTT CGA ATC C & 19 & 63.1 & 50 & $100-3000$ \\
\hline
\end{tabular}

\section{Acknowledgement}

This work was fully supported by the Agricultural Research Center, Plant Pathology Research Institute, Giza, Egypt.

\section{References}

Abd-Elsalam KA, Roshdy S, Amin OE, Rabani MY. 2010 - First morphogenetic identification of Colletotrichum musae from imported Bananas in Saudi Arabia. Genetics and Molecular Research 9, 23352342.

Abd-Elsalam KA, Bahkali BA, Moslem MA, Pierre JGM De Wit, Verreet J-A. 2011a Detection of Mycosphaerella graminicola in wheat leaves by a microsatellite dinucleotide specific-primer. International Journal of Molecular Science 12, 682-693.

Abd-Elsalam KA, Bahkali HA, Verreet J-A, Moslem M.A, 2011b - Microsatelliteprimed PCR as a tool for discrimination of Fusarium species. Journal of Food Safety 31, 35-40.

Ali SM, Dennis J. 1992 - Host range and physiological specialization of Macrophomina phaseolina isolated from field peas in South Australia. Australian Journal of Experimental Agricultural 32, 1121-1125.

Alvaro MRA, Ricardo, V. A, Carlos A.A.A, Valdemar, P.C. David, S J.F. Silvana, R.R.M, Luis CB, Mauro C.P, Claudio G.P.C. 2003 - Genotypic diversity among isolates of Macrophomina phaseolina revealed by RAPD. Fitopatologia Brasilia 28, 279-285.
Alves A, Phillips AJL, Henriques I, Correia A. 2007 - Rapid differentiation of species of Botryosphaeriaceae by PCR fingerprinting. Research Microbiology 158, 112-121.

Aly AA, Hussein EM, Mostafa MA, Ismail A.I. 1996 - Distribution, identification, and pathogenicity of Fusarium spp. isolated from some Egyptian cottons. Menofiya Journal of Agricultural Research 4, 819836

Ariasa RS, Rayb JD, Mengistuc A, Scheffler BE. 2011 - Discriminating microsatellites from Macrophomina phaseolina and their potential association to biological functions. Plant Pathology 60, 709-718.

Bahkali AH, Abd-Elsalam KA, Guo J-R, Khiyami MA and Verreet J-A. 2012 Characterization of novel di-, tri-, and tetranucleotide microsatellite primers suitable for genotyping various plant pathogenic fungi with special emphasis on Fusaria and Mycospherella graminicola. International Journal of Molecular Science 13, 2951-2964.

Baird RE, Wadl PA, Allen T, McNeill D, Wang X, Moulton JK, Rinehart TA, Abbas HK, Shier T, Trigiano RN. 2010 - Variability of United States isolates of Macrophomina phaseolina based on simple sequence repeats and cross genus transferability to related genera within Botryosphaeriaceae. Mycopathologia 170, 169-180.

Burgess T, Wingfield MJ, Wingfield BW. 2001 - Simple sequence repeat markers distinguish among morphotypes of Sphaeropsis sapinea. Applied 
Environmental and Microbiology 67, 354362.

Chakraborty BN, Chakraborty U, Dey PL. Rai K. 2011 - rDNA sequence and phylogenetic analysis of Macrophomina phaseolina, root rot pathogen of Citrus reticulata (Blanco). Global Journal of Molecular Science 6, 26-34.

Dhingra OD, Sinclair JB. 1978 - Biology and pathology of Macrophomina phaseolina. Imprensa da Universidade Federal de Viscosa, Brazil, 166pp.

Fuhlbohm M. 1997 - Genotypic diversity among Australian isolates of Macrophomina phaseolina. XX Biennial Australian Plant Pathology Society Conference, Lincoln University, New Zealand.

Godoy P. Cano J, Gene J, Guarro J, HoüflingLima A.L, Colombo A.L. 2004 Genotyping of 44 isolates of Fusarium solani, the main agent of fungal keratitis in Brazil. Journal of Clinical Microbiology 42, 4494-4497.

Grünig CR, Sieber TN, Holdenrieder O. 2001 Characterization of dark septate endophytic fungi (DSE) using intersimple-repeat-anchored polymerase chain reaction (ISSR- PCR) amplification. Mycological Research 105, 24-32.

Guerin F, Gladieux P, Le Cam B. Origin 2007 Colonization history of newly virulent strains of the phytopathogenic fungus Venturia inaequalis. Fungal Genetic and Biology 44, 284-292.

Jana T, Sharma TR, Prasad RD, Arora, DK. 2003 - Molecular characterization of Macrophomina phaseolina and Fusarium species by a single primer RAPD technique. Microbiological Research 158, 249-257.

Jana T, Sharma TR, Singh NK. 2005 - SSRbased detection of genetic variability in the charcoal root rot pathogen Macrophomina phaseolina. Mycological Research 109, 81-86.

Jany JL, Bousquet J, Gagne A, Khasa DP. 2006 - Simple sequence repeats (SSR) markers in the ectomycorrhizal fungus Laccaria bicolor for environmental monitoring of introduced strains and molecular ecology applications. Mycological Research 110, 11051-11059.

Karaoglu H, Lee CMY, Meyer W. 2005 Survey of simple sequence repeats in completed fungal genomes. Molecular Biology and Evolution 22, 639-649.

Mahdizadeh VN, Safaie E Mohammadi Goltapeh N, Mayek-Perez. 2012 Intraspecies diversity of Macrophomina phaseolina in Iran. Archives of Phytopathology and Plant Protection 45, 963-976.

Mihail JD, Taylor SJ. 1992 - Interpreting variability among isolate Macrophomina phaseolina in pathogenicity, pycnidium production and chlorate utilization. Canadian. Journal Botany 73, 1596-1603.

Mostafa MA. 1959 - Review of fungal diseases of cotton in Egypt. Egyptian Review of Science 3, 1-55.

Mwang'Ombe AW, Thiong'OG, Olubayo, FM , Kiprop EK. 2007 - DNA microsatellite analysis of Kenyan isolates of Rhizoctonis solani from common bean (Phaseolus vulgaris L.). Journal of Plant Pathology 6, 66-71.

Omar MR, Abd-Elsalam KA, Aly AA, ElSamawaty AMA , Verreet J-A. 2007 Diversity of Macrophomina phaseolina from cotton in Egypt: analysis of pathogenicity, chlorate phenotypes, and molecular characterization. Journal of Plant Diseases and Protection 114, 196204.

Purkayastha S, Kaur B, Dilbaghi N, Chaudhary. A 2006 - Characterization of Macrophomina phaseolina, the charcoal rot pathogen of cluster bean, using conventional techniques and PCR based molecular markers. Journal of Plant Pathology 55, 106-116.

Purkayastha SB, Kaur P, Arora I, Bisyer Dilbaghi N, Chaudhury A. 2008 Molecular genotyping of Macrophomina phaseolina isolates: comparison of 
microsatellite primed PCR and repetitive element sequence-based PCR. Journal of Phytopathology 156, 372-381.

Raboin LM, Selvi A, Oliveira KM, Paulet F, Calatayud C, Zapater M-F, Brottier P, Luzaran, R, Garsmeur O, Carlier J, D'Hont A. 2007 - Evidence for the dispersal of a unique lineage from Asia to America and Africa in the sugarcane fungal pathogen Ustilago scitaminea. European Journal of Plant Pathology 44, 64-76.

Reyes-Franco MC, Herna'ndez-Delgado S, Beas-Fernández R, Medina-Fernández M, Simpson J, Mayek-Pe'rez N. 2006 Pathogenic and genetic variability within Macrophomina phaseolina from Mexico and other countries. Journal of Phytopathology 154, 447-453.

Sabet KA , Khan LD . 1969 - Competitive saprophytic ability and inoculum potential of cotton root-infecting fungi in five soils. Empire Cotton Growing Review 46, 119133.

Saleh AA, Ahmed HU, Todd TC, Travers SE, Zeller KAF, Leslie J, Garrett KA. 2010 -
Relatedness of Macrophomina phaseolina isolates from tall grass prairie, maize, soybean and sorghum. Molecular Ecology 19, 79-91.

Saharan MS, Naef A, Kumar J, and Tiwari R. 2007 - Characterization of variability among isolates of $F$. graminearum associated with head scab of wheat using DNA markers. Current Science 92, 230-235.

Su G, Suh, SO, Schneider RW, Russin JS. 2001 - Host specialization in the charcoal rot fungus, Macrophomina phaseolina. Phytopathology 91, 120-126.

Vandemark G, Martnez O, PecinaV, Alvardo M de J. 2000 - Assessment of genetic relationships among isolates of Macrophomina phaseolina using simplified AFLP technique and two different methods of analysis. Mycologia, 92, 656-664.

Wöstemeyer J, Kreibich A. 2002 - Repetitive DNA elements in fungi (Mycota): impact on genomic architecture and evolution. Current Genetic 41, 189-198. 